\title{
Efeito do tamanho da semente na acumulação de biomassa e nutrientes e na produtividade do feijoeiro ${ }^{(1)}$
}

\begin{abstract}
Adriano Perin $^{(2)}$, Adelson Paulo Araújo(3) e Marcelo Grandi Teixeira ${ }^{(4)}$
Resumo - O objetivo deste trabalho foi avaliar o efeito do tamanho da semente na acumulação de biomassa e nutrientes e no rendimento de grãos de cultivares de feijoeiro (Phaseolus vulgaris L.) no campo. O delineamento experimental foi em blocos ao acaso, em esquema fatorial $3 \times 2$ com quatro repetições: três cultivares (Kaboon, Manteigão e Carioca) e dois tamanhos de semente (pequeno e grande). Foram efetuadas nove amostragens semanais de biomassa entre 14 e 70 dias após semeadura. As sementes grandes aumentaram a altura da planta, o índice de área foliar e a biomassa da parte aérea e raiz desde a primeira amostragem, mas não modificaram a massa de vagens. No início do experimento, as sementes grandes aumentaram a taxa de crescimento da cultura, mas este efeito desapareceu ao final do período amostral. Plantas originadas de sementes grandes acumularam mais $\mathrm{N}$ e $\mathrm{K}$ na parte aérea e raízes aos 49 mas não aos 70 dias após semeadura. Sementes pequenas reduziram o estande da cultivar Carioca. Não houve efeito do tamanho da semente na produção de grãos, componentes de produção e índice de colheita. Sementes de maior tamanho podem antecipar o crescimento do feijoeiro, mas plantas oriundas de sementes pequenas podem compensar seu menor crescimento inicial garantindo uma mesma produção de grãos.
\end{abstract}

Termos de indexação: Phaseolus vulgaris, taxa de crescimento, índice de colheita, componentes de rendimento.

\section{Effect of seed size on biomass and nutrient accumulation and on grain yield of common bean}

\begin{abstract}
This work intended to evaluate the effect of seed size on growth, nutrient accumulation and grain yield of common bean cultivars (Phaseolus vulgaris L.) under field conditions. The experimental design was a randomized block in a $3 \times 2$ factorial arrangement with four replicates: three cultivars (Kaboon, Manteigão and Carioca) and two seed sizes (small and large). Biomass was weekly sampled between 14 and 70 days after sowing. Large seeds increased the plant height, the leaf area index and the shoot and root biomass since the first sampling but did not affect pod biomass. At the beginning of the experiment the large seeds increased the crop growth rate, but this effect disappeared at the end of sampling period. Plants originating from large seeds accumulated more $\mathrm{N}$ and $\mathrm{K}$ in shoots and roots at 49 but not at 70 days after sowing. Small seeds reduced the stand of cultivar Carioca. There was no significant effect of seed size on grain yield, yield components and harvest index. Large seeds can anticipate the growth of bean crop, but plants originating from small seeds may compensate their slower initial growth providing a similar grain yield.
\end{abstract}

Index terms: Phaseolus vulgaris, growth rate, harvest index, yield components.

(1) Aceito para publicação em 31 de julho de 2002.

(2) Universidade Federal de Viçosa, Dep. de Fitotecnia, Avenida P. H. Rolfs, s/no, CEP 36571-000 Viçosa, MG. E-mail: ds43757@alunos.ufv.br

(3) Universidade Federal Rural do Rio de Janeiro, Dep. de Solos, CEP 23890-000 Seropédica, RJ. Bolsista do CNPq. E-mail: aparaujo@ufrrj.br

(4) Embrapa-Centro Nacional de Pesquisa de Agrobiologia, Caixa Postal 74505, CEP 23851-970 Seropédica, RJ. E-mail: grandi@cnpab.embrapa.br

\section{Introdução}

O feijoeiro comum (Phaseolus vulgaris L.) é um dos principais componentes da alimentação da população brasileira. Apesar disso, sua produtividade é muito baixa na maioria dos Estados produtores (IBGE, 2000). A melhoria do nível tecnológico desta cultura mediante uso de sementes de boa qualidade torna-se necessária para a elevação da produtivida- 
de (Bragantini, 1996). A classificação de sementes do feijoeiro por tamanho e peso pode ser uma estratégia para aumento da produtividade, visto que o tamanho da semente afeta a germinação, o vigor das plantas e a produção de grãos. Além disso, sementes de tamanho uniforme aumentam a precisão da semeadura mecânica (Krzyzanowski et al., 1991). Entretanto, a diversidade dos resultados obtidos sobre o efeito do tamanho da semente na qualidade fisiológica e desempenho no campo demandam ações de pesquisa que propiciem a adequada orientação das instituições produtoras e comercializadoras de sementes (Marcos Filho \& Avancine, 1983).

O potencial produtivo de uma cultivar de feijoeiro pode ser considerado como função da taxa de crescimento, da partição da biomassa para os sítios reprodutivos e da duração do ciclo de crescimento (Sexton et al., 1994). Admitindo-se que genótipos com sementes de diferentes tamanhos apresentem uma mesma taxa de crescimento relativo, sementes de maior massa podem propiciar maior crescimento e produtividade (White \& González, 1990). Sementes de maior tamanho geralmente possuem melhor qualidade fisiológica, o que pode ser vantajoso sob condições de estresse hídrico ou de sombreamento (White \& González, 1990). Além disso, a produção da biomassa da parte aérea e da raiz e a acumulação de $\mathrm{P}$ de genótipos de feijoeiro foram correlacionadas com a massa da semente, indicando que a eficiência de utilização de $\mathrm{P}$ está associada às reservas da semente (Yan et al., 1995). Apesar de evidências indicarem que sementes pequenas de soja apresentam redução na emergência e originam plantas de menor altura, a superioridade das sementes grandes no rendimento de grãos não foi suficientemente comprovada (Lima \& Carmona, 1999).

Por outro lado, estudos comparando genótipos de feijoeiro com sementes de diferentes tamanhos indicam uma forte relação negativa entre tamanho da semente e rendimento de grãos, embora a magnitude deste efeito tenha variado com o ambiente (White \& González, 1990). Genótipos de feijoeiro com sementes grandes apresentaram menor taxa de crescimento relativo e rendimento de grãos que genótipos de sementes pequenas (White et al., 1992); a menor taxa de crescimento relativo foi associada à baixa atividade fotossintética por unidade de área foliar (Sexton et al., 1997). Entretanto, parte desta relação negativa entre tamanho da semente e rendimento de grãos em genótipos de feijoeiro está relacionada com distintas adaptações ecológicas às diferentes regiões de domesticação (Sexton et al., 1997), e não podem ser extrapoladas para diferenças de tamanho de semente dentro de uma mesma cultivar.

Cultivares de feijoeiro podem responder de forma diferenciada ao plantio de sementes de diversos tamanhos (Figueiredo \& Vieira, 1970), demandando avaliações que considerem tais variações entre cultivares. Determinações das taxas de crescimento e da atividade fotossintética podem elucidar os mecanismos envolvidos no desempenho das cultivares de feijoeiro oriundas de sementes de diferentes tamanhos. A existência de variações no desempenho produtivo de sementes de diferentes tamanhos de uma mesma cultivar demandariam a prévia classificação das sementes por lote de tamanho, antes de sua comercialização.

O objetivo deste trabalho foi avaliar o efeito do tamanho da semente na acumulação de biomassa e nutrientes e no rendimento de grãos de cultivares de feijoeiro no campo.

\section{Material e Métodos}

$\mathrm{O}$ experimento foi realizado na Embrapa-Centro $\mathrm{Na}-$ cional de Pesquisa de Agrobiologia, Seropédica, RJ, que está situada a $22^{\circ} 45^{\prime} \mathrm{S}$ e $43^{\circ} 41^{\prime} \mathrm{O}$, e altitude de $40 \mathrm{~m}$, em solo Argissolo, entre maio e agosto de 2000. Análises de solo na profundidade de $0-20 \mathrm{~cm}$, efetuadas de acordo com Embrapa (1997), indicaram: pH em água, 4,7; Ca, $1,9 \mathrm{cmol}_{\mathrm{c}} \mathrm{kg}^{-1} ; \mathrm{Mg}, 1,5 \mathrm{cmol}_{\mathrm{c}} \mathrm{kg}^{-1} ; \mathrm{Al}, 0,1 \mathrm{cmol}_{\mathrm{c}} \mathrm{kg}^{-1}$; $\mathrm{K}, 0,18 \mathrm{cmol}_{\mathrm{c}} \mathrm{kg}^{-1} ; \mathrm{H}, 1,2 \mathrm{cmol}_{\mathrm{c}} \mathrm{kg}^{-1} ; \mathrm{P}, 3 \mathrm{mg} \mathrm{kg}^{-1}$; $\mathrm{C}, 6,9 \mathrm{~g} \mathrm{~kg}^{-1}$, textura franco-argilo-arenosa. O delineamento experimental foi em blocos ao acaso, em esquema fatorial $3 \times 2$, com quatro repetições: três cultivares de feijoeiro (Kaboon, Manteigão e Carioca) e dois tamanhos de semente (pequeno e grande). A cultivar Kaboon possui grãos brancos e hábito de crescimento determinado (tipo I); a cultivar Manteigão apresenta grãos beges e hábito de crescimento indeterminado arbustivo (tipo II); e a cultivar Carioca possui grãos beges com estrias marrons e hábito de crescimento indeterminado prostrado (tipo III). Algumas características das sementes utilizadas são apresentadas na Tabela 1. 
As parcelas possuíam sete linhas de $4 \mathrm{~m}$ espaçadas $0,5 \mathrm{~m}$, com densidade de plantio de 15 sementes $\mathrm{m}^{-1}$. No sulco de plantio foram incorporados 25,40 e $40 \mathrm{~kg} \mathrm{ha}^{-1}$ de N, P e K, respectivamente, em formulação comercial, sendo efetuada uma aplicação em cobertura de $40 \mathrm{~kg} \mathrm{ha}^{-1}$ (uréia) aos 30 dias após emergência. Durante o período experimental, os parâmetros climáticos médios foram: temperatura, $20^{\circ} \mathrm{C}$; umidade relativa, $64 \%$; evaporação de tanque, 4,4 $\mathrm{mm} \mathrm{dia}^{-1}$; insolação, 6,6 horas dia $^{-1}$. $\mathrm{O}$ experimento era irrigado sempre que necessário.

Foram efetuadas nove amostragens semanais de biomassa, entre os 14 e 70 dias após a semeadura (DAS), coletando-se as plantas em $0,5 \mathrm{~m}$ da segunda ou da sexta linha de cada parcela, e raízes retiradas com auxílio de pá reta. A altura da planta foi fornecida pela distância entre a base do caule e o meristema apical. As plantas foram separadas em raízes, caules, folhas e vagens, determinando-se a área foliar (Li-Cor 3100). Cada porção vegetal foi secada em estufa e pesada, calculando-se a área foliar por folha, a área foliar específica (razão entre área foliar e massa de folha), a razão de área foliar (razão entre área foliar e massa total), a razão folha:caule e a razão raiz:parte aérea. No material vegetal colhido aos 49 e 70 DAS, o teor de $\mathrm{N}$ foi determinado pelo método semimicro-Kjeldahl; após a digestão nitroperclórica, o teor de $\mathrm{P}$ foi determinado colorimetricamente pelo molibdato de amônio, e o de K por fotometria de chama (Malavolta et al., 1989).

Os dados foram convertidos para índice de área foliar (IAF) e biomassa por unidade de área, e transformados em logaritmo natural, para homogeneizar as variâncias das diferentes épocas de coleta. O modelo estatístico testado incluiu o efeito de cultivar, tamanho da semente, coleta (como subparcela) e suas interações. Os dados de IAF e biomassa total foram ajustados aos modelos matemáticos exponencial polinomial de $3^{\circ}$ grau e de Gompertz, respectivamente, obtendo-se, por derivação, valores instantâneos das taxas de crescimento da cultura e de assimilação líquida (Hunt, 1982).

Tabela 1. Características das sementes das cultivares de feijoeiro estudadas.

\begin{tabular}{lcccc}
\hline Tamanho & $\begin{array}{c}\text { Massa de 100 } \\
\text { grãos }(\mathrm{g})\end{array}$ & $\mathrm{N}$ & $\mathrm{P}$ & $\mathrm{K}$ \\
\hline \multicolumn{5}{c}{ Kaboon } \\
Pequena & 33,6 & 41,9 & 4,4 & 21 \\
Grande & 61,1 & 41,1 & 4,5 & 19 \\
\hline \multicolumn{5}{c}{ Manteigão } \\
Pequena & 31,8 & 42,1 & 4,1 & 20 \\
Grande & 51,5 & 43,3 & 4,4 & 19 \\
\hline \multicolumn{5}{c}{ Carioca } \\
Pequena & 15,6 & 37,8 & 4,3 & 21 \\
Grande & 28,7 & 38,0 & 4,0 & 21 \\
\hline
\end{tabular}

A colheita de grãos foi efetuada aos 83 DAS nas cultivares Kaboon e Manteigão, e aos 90 DAS na cultivar Carioca, na linha central de cada parcela (equivalente a $1,5 \mathrm{~m}^{2}$ ). Foram determinados o número de plantas, o número de vagens, o número de grãos, a biomassa da parte aérea (caule e palha das vagens) e o rendimento de grãos. Com base nesses dados, foram estimados os componentes de produção (número de vagens por planta, número de grãos por vagem e massa de 100 grãos) e o índice de colheita (razão entre a massa seca de grãos e a massa seca total da parte aérea). Os grãos colhidos foram analisados quanto aos teores de N, P e K (Malavolta et al., 1989). O modelo estatístico testado incluiu os efeitos de cultivar, tamanho da semente e sua interação.

\section{Resultados e Discussão}

Apesar de terem sido detectados efeitos significativos de cultivares e de tamanho da semente na maioria dos caracteres mensurados de produção de biomassa e acumulação de nutrientes, as interações entre os dois fatores não foram significativas. Desta forma, são apresentados apenas os resultados referentes ao efeito do tamanho da semente, na média das três cultivares.

Em todas as épocas, houve aumento significativo na altura da planta e na produção de biomassa do caule, raiz e total em plantas originadas de sementes grandes, revelando-se proporcionalmente mais intenso nas primeiras amostragens (Tabela 2). Isto sugere que as maiores reservas das sementes de maior tamanho resultam em desenvolvimento inicial mais vigoroso. Por outro lado, não foi verificado efeito do tamanho da semente na massa de vagens entre os 49 e 70 DAS. A massa de caule foi o componente mais alterado pelo tamanho da semente, corroborando a observação de Figueiredo \& Vieira (1970) de que a altura da planta - ou seja, o caule como seu tecido de sustentação - é o caráter mais afetado pelo tamanho da semente do feijoeiro; conseqüentemente, plantas oriundas de sementes grandes tiveram menor razão folha:caule durante todo o período amostral (Tabela 2).

As sementes grandes acarretaram aumentos no IAF desde os 14 DAS, originando folhas maiores, com maior área foliar por folha (Tabela 2). Os valores máximos de IAF foram registrados aos 49 DAS nas plantas oriundas de sementes grandes, 
e aos 56 DAS nas plantas oriundas de sementes pequenas. Gomes et al. (2000) também observaram valor máximo de IAF aos 56 DAS na cultivar Carioca sob irrigação. Plantas oriundas de sementes grandes apresentaram uma senescência foliar mais intensa, e aos 70 DAS não houve efeito do tamanho da semente na produção de área e de massa foliar. Além disso, o tamanho da semente não modificou a área foliar específica, a razão de área foliar e a razão raiz:parte aérea das plantas do feijoeiro (Tabela 2).

A taxa de crescimento da cultura (TCC), que expressa a velocidade de acumulação de biomassa por unidade de terreno, foi superior nas plantas oriundas de sementes de maior tamanho, principalmente durante os estádios iniciais do cultivo (Figura 1). Entretanto, a partir dos 65 DAS, os tratamentos com sementes pequenas ou grandes apresentaram valores similares de TCC. Nas plantas oriundas de sementes grandes, a TCC atingiu valor máximo de $24,3 \mathrm{~g} \mathrm{~m}^{-2} \mathrm{dia}^{-1}$ aos 53 DAS, enquanto nas plantas oriundas de sementes pequenas a TCC máxima, de $22,8 \mathrm{~g} \mathrm{~m}^{-2} \mathrm{dia}^{-1}$, foi observada aos 60 DAS. Tais resultados indicam que sementes pequenas de feijoeiro induzem a um crescimento inicial mais lento, mas que pode ser compensado em estágios posteriores da ontogenia vegetal.

A taxa de assimilação líquida (TAL), que exprime a velocidade de acumulação de biomassa por unidade de área foliar, e estima a fotossíntese líquida do dossel, teve valores decrescentes até cerca de 40 DAS (Figura 1). Esse resultado indica uma diminuição da atividade fotossintética com a ontogenia

Tabela 2. Altura da planta, massa seca de folha, caule, vagem, raiz e total, índice de área foliar, área foliar por folha, área foliar específica, razão de área foliar, razão folha:caule e razão raiz:parte aérea de plantas de feijoeiro originadas de sementes pequenas (SP) e sementes grandes (SG), em nove épocas de coleta (médias dos dados originais de três cultivares, transformados em logaritmo natural antes da análise estatística).

\begin{tabular}{|c|c|c|c|c|c|c|c|c|c|c|c|c|}
\hline \multirow[t]{2}{*}{$\begin{array}{l}\text { Dias após } \\
\text { semeadura }\end{array}$} & \multicolumn{2}{|c|}{$\begin{array}{l}\text { Altura da planta } \\
\quad(\mathrm{cm})\end{array}$} & \multicolumn{2}{|c|}{$\begin{array}{l}\text { Massa seca da } \\
\text { folha }\left(\mathrm{g} \mathrm{m}^{-2}\right)\end{array}$} & \multicolumn{2}{|c|}{$\begin{array}{c}\text { Massa seca do } \\
\text { caule }\left(\mathrm{g} \mathrm{m}^{-2}\right)\end{array}$} & \multicolumn{2}{|c|}{$\begin{array}{l}\text { Massa seca da } \\
\text { vagem }\left(\mathrm{g} \mathrm{m}^{-2}\right)\end{array}$} & \multicolumn{2}{|c|}{$\begin{array}{c}\text { Massa seca da } \\
\text { raiz }\left(\mathrm{g} \mathrm{m}^{-2}\right)\end{array}$} & \multicolumn{2}{|c|}{$\begin{array}{l}\text { Massa seca } \\
\text { total }\left(\mathrm{g} \mathrm{m}^{-2}\right)\end{array}$} \\
\hline & SP & SG & SP & SG & SP & SG & SP & SG & SP & SG & SP & SG \\
\hline 14 & 7 & $9 *$ & 5 & $9 *$ & 1,3 & $2,8^{*}$ & - & - & 3,7 & $5,8 *$ & 10 & $18^{*}$ \\
\hline 21 & 11 & $13^{*}$ & 20 & $28 *$ & 3,9 & $6,2^{*}$ & - & - & 4,8 & $6,6^{*}$ & 28 & $41^{*}$ \\
\hline 28 & 17 & $20 *$ & 34 & $48 *$ & 12 & $17 *$ & - & - & 7,0 & $8,8^{*}$ & 52 & $75^{*}$ \\
\hline 35 & 26 & $31 *$ & 66 & $72 *$ & 21 & $28 *$ & - & - & 5,2 & $6,8^{*}$ & 92 & $107 *$ \\
\hline 42 & 38 & $44^{*}$ & 92 & $109 *$ & 46 & $57 *$ & - & - & 7,5 & $10,3^{*}$ & 145 & $176^{*}$ \\
\hline 49 & 43 & $51^{*}$ & 111 & $138 *$ & 65 & $91 *$ & 13 & 15 & 8,7 & $11,5^{*}$ & 198 & $256^{*}$ \\
\hline 56 & 47 & $56^{*}$ & 121 & 130 & 84 & $109 *$ & 55 & 52 & 15,6 & $19,2 *$ & 275 & $311 *$ \\
\hline 63 & 52 & $60^{*}$ & 95 & $113 *$ & 73 & $96^{*}$ & 118 & 138 & 12,5 & $14,2 *$ & 299 & $361 *$ \\
\hline \multirow[t]{3}{*}{70} & 50 & $53^{*}$ & 155 & 151 & 87 & $121^{*}$ & 256 & 297 & 14,1 & $16,4^{*}$ & 512 & $586^{*}$ \\
\hline & \multicolumn{2}{|c|}{$\begin{array}{l}\text { Índice de } \\
\text { área foliar } \\
\left(\mathrm{m}^{2} \mathrm{~m}^{-2}\right)\end{array}$} & \multicolumn{2}{|c|}{$\begin{array}{l}\text { Área foliar } \\
\text { por folha } \\
\left(\mathrm{cm}^{2}\right)\end{array}$} & \multicolumn{2}{|c|}{$\begin{array}{l}\text { Área foliar } \\
\text { específica } \\
\left(\mathrm{cm}^{2} \mathrm{~g}^{-1}\right)\end{array}$} & \multicolumn{2}{|c|}{$\begin{array}{l}\text { Razão de } \\
\text { área foliar } \\
\left(\mathrm{cm}^{2} \mathrm{~g}^{-1}\right)\end{array}$} & \multicolumn{2}{|c|}{$\begin{array}{c}\text { Razão } \\
\text { folha:caule } \\
\left(\mathrm{g} \mathrm{g}^{-1}\right)\end{array}$} & \multicolumn{2}{|c|}{$\begin{array}{l}\text { Razão raiz: } \\
\text { parte aérea } \\
\left(\mathrm{mg} \mathrm{g}^{-1}\right)\end{array}$} \\
\hline & SP & SG & SP & SG & SP & SG & SP & SG & SP & SG & SP & SG \\
\hline 14 & 0,16 & $0,26 *$ & 32 & $48 *$ & 312 & 301 & 166 & 153 & 4,17 & $3,52 *$ & 166 & 153 \\
\hline 21 & 0,55 & $0,81 *$ & 58 & $68 *$ & 320 & 331 & 197 & 200 & 5,15 & 5,28 & 197 & 200 \\
\hline 28 & 1,01 & $1,43^{*}$ & 91 & $100 *$ & 307 & 307 & 201 & 193 & 3,53 & $2,92 *$ & 201 & 193 \\
\hline 35 & 1,84 & $2,23^{*}$ & 106 & $119 *$ & 282 & 321 & 205 & 212 & 3,39 & $2,71 *$ & 205 & 212 \\
\hline 42 & 2,48 & $2,91 *$ & 94 & $100 *$ & 267 & 264 & 171 & 164 & 2,17 & $1,98^{*}$ & 171 & 164 \\
\hline 49 & 2,79 & $3,84^{*}$ & 89 & $105^{*}$ & 252 & 280 & 141 & 151 & 1,69 & $1,57 *$ & 141 & 151 \\
\hline 56 & 2,84 & $3,18^{*}$ & 91 & $100 *$ & 235 & 249 & 105 & 103 & 1,46 & $1,21 *$ & 105 & 103 \\
\hline 63 & 1,98 & $2,39 *$ & 69 & $77 *$ & 211 & 213 & 68 & 66 & 1,32 & $1,17 *$ & 68 & 66 \\
\hline 70 & 2,24 & 2,33 & 57 & 60 & 149 & 158 & 44 & 40 & 1,75 & $1,28 *$ & 44 & 40 \\
\hline
\end{tabular}

*Diferença significativa entre sementes pequenas e sementes grandes pelo teste de Tukey a $5 \%$ de probabilidade. 
vegetal, o que pode ser atribuído principalmente ao auto-sombreamento decorrente da expansão foliar (Hunt, 1982). Houve pequeno incremento da TAL após os 42 DAS, o que pode ocorrer em leguminosas em resposta ao estímulo à atividade fotossintética ocasionado pela maior demanda por assimilados quando do rápido enchimento dos grãos (Sivakumar $\&$ Shaw, 1978). Apesar das dificuldades envolvidas na comparação estatística das estimativas da TAL (Hunt, 1982), pode-se inferir que essa taxa foi pouco afetada pelo tamanho da semente (Figura 1). Portanto, as sementes com maiores reservas favoreceram o crescimento vegetal principalmente em virtude do aumento da área foliar, e não da atividade fotossintética. Sexton et al. (1997) observaram que a menor taxa de crescimento de genótipos de feijoeiro de sementes grandes estava associada à sua menor atividade fotossintética, mas essas variações foram principalmente um reflexo das diferentes regiões de domesticação dos distintos pools gênicos, e não podem explicar as diferenças nas taxas de crescimento observadas dentro de uma mesma cultivar (Figura 1).

Plantas originadas de sementes grandes tiveram maior acúmulo de $\mathrm{N}$ e $\mathrm{K}$ na parte aérea e raízes aos 49 DAS, mas a acumulação de P não foi modificada (Tabela 3). Aos 70 DAS, o tamanho da semente não afetou a acumulação de nutrientes pelo feijoeiro, exceto pelo aumento no conteúdo de $\mathrm{K}$ no caule de plantas oriundas de sementes grandes. O tamanho da semente não afetou os teores de $\mathrm{P}$ e $\mathrm{K}$ nos tecidos vegetais nas duas épocas avaliadas, assim como os teores de N aos 49 DAS. Desta forma, a maior acumulação de N e K na parte aérea e raízes aos 49 DAS, nas plantas oriundas de sementes grandes, foi conseqüência de maior produção de biomassa (Tabela 2), e não da maior concentração desses nutrientes nos tecidos. Por outro lado, aos 70 DAS os teores de $\mathrm{N}$ no caule e na vagem foram superiores nas plantas originadas de sementes pequenas (Tabela 3 ).

A análise de variância dos caracteres relacionados à produção de grãos e componentes de produção indicou alguns efeitos significativos de cultivar, efeitos não significativos de tamanho da semente, e poucas interações significativas entre tamanho da semente e cultivar. As três cultivares tiveram produção de grãos similares, mas os componentes de produção contribuíram de forma diferenciada com o rendimento de cada cultivar (Tabela 4). Assim, a cultivar Carioca apresentou o maior número de vagens por planta e número de grãos por vagem, mas com menor massa de 100 grãos. Paralelamente, essa cultivar teve maior índice de colheita, associado à pequena massa de caule e de palhada de vagens na maturação, indicando maior eficiência na translocação de biomassa para os grãos.
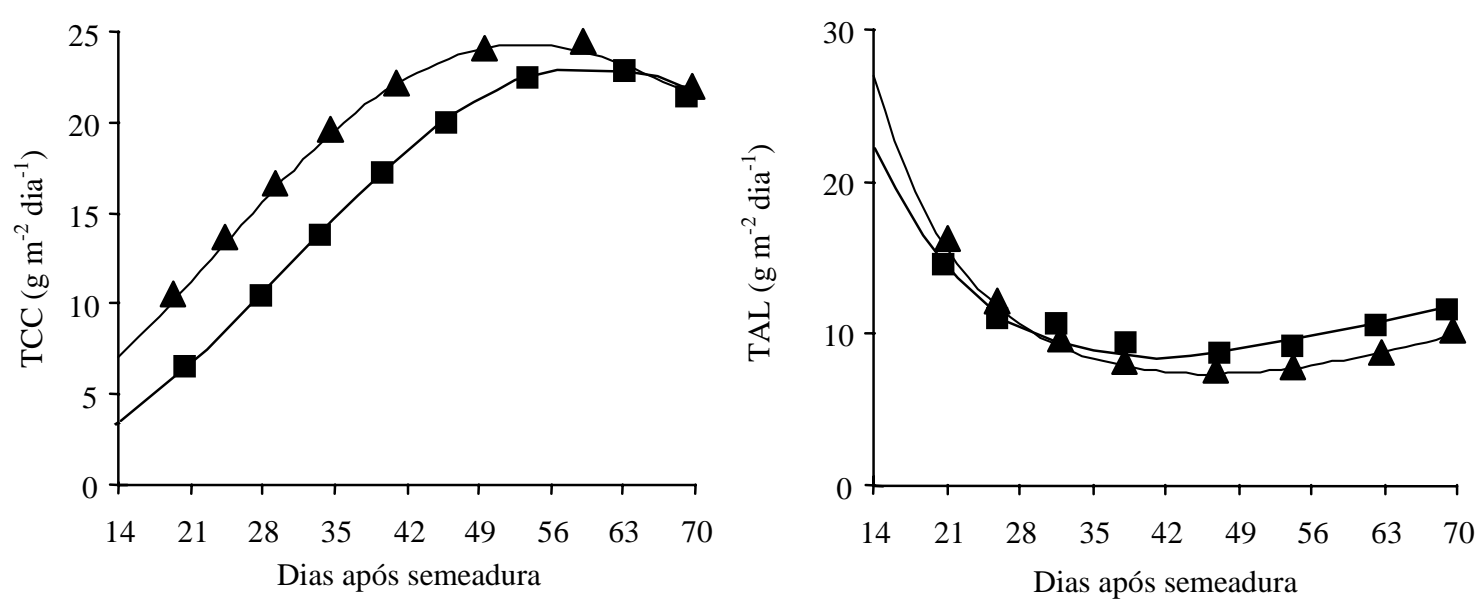

Figura 1. Taxa de crescimento da cultura (TCC) e taxa de assimilação líquida (TAL) de plantas de feijoeiro originadas de sementes pequenas $(\boldsymbol{\square})$ e sementes grandes $(\mathbf{\Lambda})$ (médias de três cultivares). 
Apesar da tendência de aumento da produção de grãos nas plantas originadas de sementes grandes, particularmente na cultivar Carioca, não detectou-se efeito significativo do tamanho da semente no rendimento (Tabela 4), confirmando resultados de Figueiredo \& Vieira (1970) e Marcos Filho \& Avancine (1983). Além disso, o tamanho da semente não afetou os teores e os conteúdos de $\mathrm{N}, \mathrm{P}$ e $\mathrm{K}$ nos grãos das cultivares avaliadas. A cultivar Carioca, quando originada de sementes pequenas, apresentou menor núme-

Tabela 3. Teores e conteúdos de N, P e K nas porções vegetais de plantas de feijoeiro, originadas de sementes pequenas (SP) e sementes grandes (SG), em duas épocas de coleta (médias de três cultivares).

\begin{tabular}{|c|c|c|c|c|}
\hline \multirow[t]{2}{*}{ Caráter } & \multicolumn{2}{|c|}{$\begin{array}{l}49 \text { dias após } \\
\text { semeadura }\end{array}$} & \multicolumn{2}{|c|}{$\begin{array}{c}70 \text { dias após } \\
\text { semeadura }\end{array}$} \\
\hline & SP & SG & SP & SG \\
\hline & \multicolumn{4}{|c|}{$\mathrm{N}\left(\mathrm{mg} \mathrm{g}^{-1}\right)$} \\
\hline Folha & 39,9 & 38,0 & 22,9 & 22,6 \\
\hline Caule & 21,2 & 20,4 & 10,5 & $8,8^{*}$ \\
\hline Vagem & - & - & 23,0 & $20,5^{*}$ \\
\hline \multirow[t]{2}{*}{ Raiz } & 12,9 & 13,2 & 8,3 & 7,7 \\
\hline & \multicolumn{4}{|c|}{$\mathrm{P}\left(\mathrm{mg} \mathrm{g}^{-1}\right)$} \\
\hline Folha & 3,3 & 3,1 & 1,6 & 1,6 \\
\hline Caule & 2,8 & 2,7 & 1,0 & 0,9 \\
\hline Vagem & - & - & 1,9 & 1,8 \\
\hline \multirow[t]{2}{*}{ Raiz } & 1,1 & 1,1 & 0,6 & 0,5 \\
\hline & \multicolumn{4}{|c|}{$\mathrm{K}\left(\mathrm{mg} \mathrm{g}^{-1}\right)$} \\
\hline Folha & 38 & 37 & 10 & 10 \\
\hline Caule & 37 & 37 & 12 & 12 \\
\hline Vagem & - & - & 17 & 16 \\
\hline \multirow[t]{2}{*}{ Raiz } & 19 & 21 & 4,9 & 5,0 \\
\hline & \multicolumn{4}{|c|}{$\mathrm{N}\left(\mathrm{g} \mathrm{m}^{-2}\right)$} \\
\hline Folha & 4,44 & 5,23 & 3,49 & 3,29 \\
\hline Caule & 1,37 & $1,83^{*}$ & 0,95 & 1,06 \\
\hline Vagem & - & - & 5,79 & 5,96 \\
\hline Parte aérea & 5,82 & $7,07 *$ & 10,2 & 10,3 \\
\hline \multirow[t]{2}{*}{ Raiz } & 0,11 & $0,15^{*}$ & 0,12 & 0,13 \\
\hline & \multicolumn{4}{|c|}{$\mathrm{P}\left(\mathrm{g} \mathrm{m}^{-2}\right)$} \\
\hline Folha & 0,37 & 0,42 & 0,25 & 0,25 \\
\hline Caule & 0,18 & 0,24 & 0,09 & 0,11 \\
\hline Vagem & - & - & 0,46 & 0,52 \\
\hline Parte aérea & 0,55 & 0,66 & 0,80 & 0,88 \\
\hline \multirow[t]{2}{*}{ Raiz } & 0,010 & 0,012 & 0,008 & 0,009 \\
\hline & \multicolumn{4}{|c|}{$\mathrm{K}\left(\mathrm{g} \mathrm{m}^{-2}\right)$} \\
\hline Folha & 4,1 & $5,1^{*}$ & 1,5 & 1,4 \\
\hline Caule & 2,4 & $3,3^{*}$ & 1,0 & $1,4^{*}$ \\
\hline Vagem & - & - & 4,4 & 4,8 \\
\hline Parte aérea & 6,5 & $8,4^{*}$ & 7,0 & 7,6 \\
\hline Raiz & 0,17 & $0,24^{*}$ & 0,07 & 0,08 \\
\hline
\end{tabular}

*Diferença significativa entre sementes pequenas e sementes grandes pelo teste $\mathrm{F}$ a $5 \%$ de probabilidade. ro final de plantas por unidade de área do que as demais cultivares; já quando oriundas de sementes grandes, as cultivares não diferiram no estande final (Tabela 4). Marcos Filho \& Avancine (1983) também observaram redução no número final de plantas da cultivar Carioca quando oriunda de sementes pequenas. Tal fato pode indicar uma menor capacidade de sobrevivência da cultivar Carioca quando originada de sementes pequenas, o que pode refletir-se no rendimento da cultura, notadamente sob condições ambientais adversas.

Tabela 4. Produção de grãos, componentes da produção e índice de colheita de três cultivares de feijoeiro, originadas de sementes pequenas (SP) e sementes grandes $(\mathrm{SG})^{(1)}$.

\begin{tabular}{|c|c|c|c|}
\hline Cultivar & $\begin{array}{l}\text { Semente } \\
\text { pequena }\end{array}$ & $\begin{array}{c}\text { Semente } \\
\text { grande }\end{array}$ & Média \\
\hline & \multicolumn{3}{|c|}{ Produção de grãos $\left(\mathrm{g} \mathrm{m}^{-2}\right)$} \\
\hline Kaboon & 194 & 192 & 193 \\
\hline Manteigão & 195 & 218 & 206 \\
\hline Carioca & 184 & 209 & 197 \\
\hline \multirow[t]{2}{*}{ Média } & 191 & 206 & \\
\hline & \multicolumn{3}{|c|}{ Número de plantas $\left(\mathrm{m}^{-2}\right)$} \\
\hline Kaboon & $28 \mathrm{a}$ & $28 \mathrm{a}$ & $28 \mathrm{a}$ \\
\hline Manteigão & $28 \mathrm{a}$ & $29 a$ & $28 \mathrm{a}$ \\
\hline Carioca & $25 b$ & $29 a^{*}$ & $27 \mathrm{a}$ \\
\hline \multirow[t]{2}{*}{ Média } & 27 & 28 & \\
\hline & \multicolumn{3}{|c|}{ Número de vagens por planta } \\
\hline Kaboon & 4,3 & 4,8 & $4,6 b$ \\
\hline Manteigão & 4,5 & 4,5 & $4,5 b$ \\
\hline Carioca & 6,7 & 6,4 & $6,6 a$ \\
\hline \multirow[t]{2}{*}{ Média } & 5,2 & 5,3 & \\
\hline & \multicolumn{3}{|c|}{ Número de grãos por vagem } \\
\hline Kaboon & 3,4 & 3,0 & $3,2 \mathrm{c}$ \\
\hline Manteigão & 3,8 & 3,9 & $3,9 b$ \\
\hline Carioca & 5,0 & 4,7 & $4,9 \mathrm{a}$ \\
\hline \multirow[t]{2}{*}{ Média } & 4,0 & 3,9 & \\
\hline & \multicolumn{3}{|c|}{ Massa de 100 grãos (g) } \\
\hline Kaboon & $49 a$ & $48 \mathrm{a}$ & $49 a$ \\
\hline Manteigão & $41 b$ & $45 b^{*}$ & $43 b$ \\
\hline Carioca & $25 \mathrm{c}$ & $24 \mathrm{c}$ & $24 c$ \\
\hline \multirow[t]{2}{*}{ Média } & 38 & 39 & \\
\hline & \multicolumn{3}{|c|}{ Índice de colheita $\left(\mathrm{g} \mathrm{g}^{-1}\right)$} \\
\hline Kaboon & 0,53 & 0,54 & $0,53 b$ \\
\hline Manteigão & 0,55 & 0,54 & $0,54 b$ \\
\hline Carioca & 0,59 & 0,60 & $0,59 \mathrm{a}$ \\
\hline Média & 0,56 & 0,56 & \\
\hline
\end{tabular}


O tamanho da semente não modificou o número de vagens por planta, o número de grãos por vagem e o índice de colheita das três cultivares (Tabela 4). Evidências indicam que o índice de colheita é um caráter relativamente estável de uma cultivar (Spaeth et al., 1984), e que a maior parte da variância genotípica na produção de grãos de feijão está associada a variações na produção de biomassa e não no índice de colheita (Scully \& Wallace, 1990). As sementes grandes aumentaram a massa de 100 grãos da cultivar Manteigão, sem efeito nas demais cultivares. A ausência de efeito do tamanho da semente na massa de 100 grãos sugere que a seleção das sementes por classe de tamanho foi de natureza fenotípica, não acarretando separação genotípica em linhagens com diferentes tamanhos de grãos dentro da mesma cultivar (Figueiredo \& Vieira, 1970). Em relação à cultivar Manteigão, a colheita de grãos maiores no tratamento com sementes grandes pode indicar a possibilidade de seleção genotípica para tamanho da semente dentro desta cultivar.

Apesar de as sementes grandes terem aumentado a biomassa da parte aérea e da raiz entre os $14 \mathrm{e}$ 70 DAS (Tabela 2), e a TCC no início do ciclo (Figura 1), esse maior crescimento não resultou em incremento na produção de grãos (Tabela 4). Além disso, as sementes grandes acarretaram aumento da acumulação de $\mathrm{N}$ e K apenas aos 49 DAS (Tabela 3). A similaridade do índice de colheita nos tratamentos com sementes pequenas e grandes (Tabela 4), assim como da massa seca de vagens (Tabela 2), indica que o tamanho da semente não afetou o processo de translocação de assimilados da biomassa vegetativa para os grãos, e que os rendimentos semelhantes desses tratamentos foram obtidos a partir de uma biomassa preexistente também similar. O maior teor de $\mathrm{N}$ nas folhas e caules nas plantas oriundas de sementes pequenas aos 70 DAS (Tabela 3) pode indicar maior atividade metabólica ao final do ciclo, contra a senescência mais intensa nas plantas originadas de sementes grandes, detectada a partir da redução mais acentuada no IAF (Tabela 2). Dessa forma, as plantas originadas de sementes pequenas compensariam seu menor crescimento inicial com maior atividade em estágios finais da ontogenia, produzindo biomassa final similar às plantas originadas de sementes grandes e, mantendo-se estável o índice de colheita dentro de cada cultivar, fornecendo produções de grãos similares (Tabela 4).

Durante a fase experimental, não foram observadas restrições ambientais ao desenvolvimento da cultura. Pode-se admitir que, sob condições de estresse ambiental, tais como déficit hídrico ou incidência de pragas e doenças, a redução no crescimento inicial da cultura do feijoeiro acarretado pelas sementes de menor tamanho pode refletir-se em perdas de produtividade, particularmente caso esses estresses incidam no início da fase reprodutiva, quando as plantas com menor biomassa poderiam não recuperar-se satisfatoriamente para compensar menor crescimento inicial. Sob condições de temperatura média muito baixa, genótipos de feijoeiro de sementes pequenas tiveram rendimentos muito inferiores aos genótipos de sementes grandes (White \& González, 1990).

Esses resultados demonstram que plantas de feijoeiro originadas de sementes pequenas apresentam crescimento inicial mais lento, mas podem compensá-lo posteriormente na ontogenia, garantindo ao final do ciclo uma mesma produção de grãos. Isto não significa que a classificação de sementes não seja necessária, pois sementes de tamanho padronizado podem propiciar maior precisão na semeadura mecanizada, uniformidade no dossel e economia na quantidade de sementes (Lima \& Carmona, 1999).

\section{Conclusões}

1. Sementes de maior tamanho de uma mesma cultivar de feijoeiro aumentam a acumulação da biomassa da parte aérea e das raízes, a acumulação de $\mathrm{N}$ e $\mathrm{K}$ e a taxa de crescimento da cultura, particularmente no início do ciclo.

2. Plantas oriundas de sementes pequenas de cultivar de feijoeiro podem compensar menor crescimento inicial em estágios posteriores do ciclo, garantindo produção de grãos similar às plantas originadas de sementes grandes.

\section{Referências}

BRAGANTINI, C. Produção de sementes. In: ARAUJO, R. S.; RAVA, C. A.; STONE, L. F.; ZIMMERMANN, 
M. J. O. (Coord.). Cultura do feijoeiro comum no Brasil. Piracicaba: Potafos, 1996. p. 639-667.

EMBRAPA. Centro Nacional de Pesquisa de Solos (Rio de Janeiro, RJ). Manual de métodos de análise de solo. 2. ed. Rio de Janeiro, 1997. 212 p.

FIGUEIREDO, M. S.; VIEIRA, C. Efeito do tamanho das sementes sobre o "stand", produção e altura das plantas, na cultura do feijão (Phaseolus vulgaris L.). Revista Ceres, Viçosa, MG, v. 17, n. 91, p. 47-60, 1970.

GOMES, A. A.; ARAÚJO, A. P.; ROSSIELLO, R. O. P.; PIMENTEL, C. Acumulação de biomassa, características fisiológicas e rendimento de grãos em cultivares de feijoeiro irrigado e sob sequeiro. Pesquisa Agropecuária Brasileira, Brasília, v. 35, n. 10, p. 1927-1937, out. 2000.

HUNT, R. Plant growth curves: the functional approach to plant growth analysis. London: E. Arnold, 1982. 248 p.

IBGE (Rio de Janeiro, RJ). Tabela 21: colheita e valor da produção dos principais produtos da lavoura temporária, segundo as grandes regiões e unidades da federação. In:

Censo agropecuário 1995-1996: Brasil. Rio de Janeiro, 2000. Disponível em: <www.ibge.gov.br/home/ estatistica/economia/agropecuaria/censoagro >. Acesso em: out. 2000.

KRZYZANOWSKI, F. C.; FRANÇA-NETO, J. B.; COSTA, N. P. Efeito da classificação de sementes de soja por tamanho sobre sua qualidade e a precisão de semeadura. Revista Brasileira de Sementes, Brasília, v. 13, n. 1, p. 59-68, 1991.

LIMA, A. M. M. P.; CARMONA, R. Influência do tamanho da semente no desempenho produtivo da soja. Revista Brasileira de Sementes, Brasília, v. 21, n. 1, p. $157-$ 163, 1999.

MALAVOLTA, E.; VITTI, G. C.; OLIVEIRA, S. A. Avaliação do estado nutricional das plantas. Piracicaba: Associação Brasileira para Pesquisa da Potassa e do Fosfato, 1989. 201 p.
MARCOS FILHO, J.; AVANCINE, F. Tamanho da semente de feijão e desempenho do feijoeiro. Pesquisa Agropecuária Brasileira, Brasília, v. 18, n. 9, p. 10011008, set. 1983.

SCULLY, B. T.; WALLACE, D. H. Variation and relationship of biomass, growth rate, harvest index, and phenology to yield of common bean. Journal of the American Society for Horticultural Science, Alexandria, v. 115, p. 218-225, 1990.

SEXTON, P. J.; PETERSON, C. M.; BOOTE, K. J.; WHITE, J. W. Early-season growth in relation to region of domestication, seed size, and leaf traits in common bean. Field Crops Research, Amsterdam, v. 52, p. 69-78, 1997.

SEXTON, P. J.; WHITE, J. W.; BOOTE, K. J. Yielddetermining processes in relation to cultivar seed size of common bean. Crop Science, Madison, v. 34, p. 84-91, 1994.

SIVAKUMAR, M. V. K.; SHAW, R. H. Methods of growth analysis in field-grown soya beans (Glycine max (L.) Merrill). Annals of Botany, London, v. 42, p. 213222, 1978 .

SPAETH, S. C.; RANDALL, H. C.; SINCLAIR, T. R.; VENDELAND, J. S. Stability of soybean harvest index. Agronomy Journal, Madison, v. 76, p. 482-486, 1984.

WHITE, J. W.; GONZÁLEZ, A. Characterization of the negative association between seed yield and seed size among genotypes of common bean. Field Crops Research, Amsterdam, v. 23, p. 159-175, 1990.

WHITE, J. W.; SINGH, S. P.; PINO, C.; RIOS, B. M. J.; BUDDENHAGEN, I. Effects of seed size and photoperiod response on crop growth and yield of common bean. Field Crops Research, Amsterdam, v. 28, p. 295-307, 1992.

YAN, X.; LYNCH, J. P.; BEEBE, S. E. Genetic variation for phosphorus efficiency of common bean in contrasting soil types - I: vegetative response. Crop Science, Madison, v. 35, p. 1086-1093, 1995. 